\title{
CRIMINAL LIABILITY FOR FAILURES TO ACT
}

\author{
JoHN KLEINIG*
}

\section{INTRODUCTION}

In Anglo-American law, the failure to act provides a ground for criminal sanctions only where there is a pre-existing legal duty to act. ${ }^{1}$ This rule is no innocent truism, for it encompasses those cases in which the failure to act consists of a failure to respond to urgent need. Easily rendered assistance to a drowning or otherwise imperilled child is not required unless the nonrescuer stands in some legally recognized relationship to the child, and the relationship is deemed to imply or mandate a welfare duty to that child. Over the years, the extent and terms of that legally recognized relationship have been broadened. The duty to render easy aid which had its roots in common law duties (in particular, those of a parent toward his dependent children), was gradually extended to contractually based relationships (such as those between a master and his apprentice), and later widened to encompass certain relationships based on informal "undertakings." But the result still falls far short of the rule in most European legal systems, namely, a requirement that a

Copyright $(\mathcal{C} 1986$ by Law and Contemporary Problems

* Associate Professor of Philosophy, Macquarie University, New South Wales, Australia; Professor of Philosophy, John Jay College of Criminal Justice, City University of New York.

The text of this article was prepared for a Conference on Responsibility at Duke University, April 18-19, 1985. However, parts and versions of it were read to philosophy colloquia at the University of Arizona, Tucson; the Graduate Center, City University of New York; and at a meeting of the Philosophy and Law Group, New York University Law School. In addition, I had valuable discussions with William Heffernan and Tziporah Kasachkoff. Moreover, Michael Gorr, James Hallmark, Andrew von Hirsch, Douglas Husak, and Robert Young were kind enough to provide me with some written comments. Had I responded to every worthwhile suggestion and criticism, the paper would never have been completed. Therefore, I have not attempted to accommodate Christopher Schroeder's observations in this revised version.

1. Exceptions to this Anglo-American aversion can be found in Vermont and Minnesota. See Woozley, A Duty to Rescue: Some Thoughts on Criminal Liability, 69 VA. L. Rev. 1274 (1983). For treatments of the Anglo-American position, see generally The Good Samaritan and the LAW (J. Radcliff ed. 1965) [hereinafter cited as The Good SamarrTan]; Benditt, Liability for Failing to Rescue, 1 Law \& Phil. 391 (1982); D'Amato, The "Bad Samaritan" Paradigm, 70 Nw. U.L. Rev. 798 (1975); Frankel, Criminal Omissions: A Legal Microcosm, 11 WAYNE L. Rev. 367 (1965); Glazebrook, Criminal Omissions: The Duty Requirement in Offences Against the Person, 76 L.Q. REv. 386 (1960); Gregory, Gratuitous Underlakings and the Duty of Care, 1 DE PavL L. Rev. 30 (1951); Hughes, Criminal Omissions, 67 Yale L.J. 590 (1958); Kirchheimer, Criminal Omissions, 55 Harv. L. Rev. 615 (1942); Mack, Bad Samaritanism and the Causation of Harm, PHIL. \& PuB. Afr. 230 (1980); Perkins, Negative Acts in Criminal Law, 22 Iowa L. Rev. 659 (1937); Shuman, Act and Omission in Criminal Law: Towards a Nonsubjective Theory, 17 J. Legal Educ. 16 (1964); Smith, Liability for Omissions in Criminal Law, 4 Legal. Stud. 88 (1984); Snyder, Liability for Negative Conduct, 35 VA. L. Rev. 446 (1949); Weinrib, The Case for a Duty to Rescue, 90 Yale L.J. 247 (1980). 
bystander render easy aid to the gravely imperilled, provided he has recognized the opportunity to give assistance and has the ability to do so. ${ }^{2}$

Why should the requirement to render easy aid be construed so narrowly in Anglo-American law? Many reasons have been proffered-some conceptual, some jurisprudential, some moral, some practical. I do not propose to consider them all in this article. My discussion will be confined to two issues that are most likely to be of interest to philosophers. The first concerns the status of failures to act-whether failures to act can be construed as conduct for legal purposes. The second concerns the causal significance of failures to act-whether failures to act can be so related to harms that it is appropriate to contemplate criminal liability for these failures. The two issues are closely connected. Whether failures to act will be eligible for a place in causal explanation will depend significantly on conclusions reached concerning their ontological status.

My starting point is an investigation of some of the vocabulary by means of which various failures to act are signalled. This endeavor will serve as a basis for distinguishing failures to act from certain other kinds of nondoing to which they are often assimilated or with which they are often confused.

\section{The Language of Omissions}

Deeply embedded in our moral tradition is a distinction between commission and omission. Some writers have been tempted to use this distinction to limit the sphere of our moral accountability, viewing commissions alone as a basis for ascribing responsibility. Traditionally, however, the distinction has been used to extend the boundaries of accountability beyond commission into the sphere of nondoings, those nondoings which can be characterized as omissions being deemed appropriate loci for judgments of responsibility. We may be held to account not only for things done, but also for things left undone. It is, therefore, not surprising that a rich and extensive vocabulary of omission, a restricted but complex cluster of concepts carved out of the apparent "void" of nondoing, has evolved. Within this domain of omission, we may speak not only of "omitting" in a narrower sense, ${ }^{3}$ but also of "neglecting," "refraining," "forbearing," "abstaining," "declining," "refusing," "evading," "ignoring," "postponing," "shirking," "allowing," "permitting," and "letting happen." I do not, of course, intend to argue that the interest in allocating responsibility constitutes the sole reason for differentiating between the various kinds of

2. For comparative surveys, see Feldbrugge, Good and Bad Samaritans: A Comparative Survey of Criminal Law Provisions Concerning Failure to Rescue, 14 AM. J. Comp. L. 630 (1966); Rudzinski, The Duly to Rescue: A Comparative Analysis, in The Good Samaritan, supra note 1, at 91; Note, The Failure to Rescue: A Comparative Study, 52 Colum. L. Rev. 631 (1952); Note, Stalking the Good Samaritan: Communists, Capitalists and the Duty to Rescue, 1976 Utah L. Rev. 529.

3. In this article I shall use the noun "omission(s)" when making a general contrast between "commission" and "omission," and the verb "omit" when referring to that more narrowly defined form of omission, in which it contrasts or overlaps with "refrain," "neglect,"and so forth. 
omission. Nevertheless, the normative interest is pervasive and cannot be ignored.

In order to provide a better grasp of some of the main contours of the omission domain, I want first to join with what has become a lively debate in action theory about the characterization and logical topography of the central concepts concerning omissions. ${ }^{4}$ Because the debate has become highly dialogical, I shall concentrate on providing what I believe are defensible analyses of the concepts, ${ }^{5}$ relegating most of my discussion of other positions to footnotes.

One of the most general terms of omissive nondoing is "failing to act." 6 We may say that

$S$ fails to do $a$ if and only if:

(1) $S$ does not do $a$; and

(2) $a$ is reasonably expected of $S$, because

(a) $S$, or those in $S$ 's position, ordinarily do $a$; or

(b) $S$ has a responsibility to do $a$; or

(c) $S$ is obligated to do $a$; or

4. See, e.g., E. D'Arcy, Human Acts: An Essay in Their Moral Evaluation 43 (1963); J. Feinberg, Harm to Others (1984); J. Thomson, Acts and Other Events (1977); G. von Wright, Norm and Action (1963); Abelson, To Do or Let Happen, 19 Am. Phil. Q. 219 (1982); Baldwin, Foresight and Responsibility, 34 Philosophy 347 (1979); Baumrin \& Lupu, A Common Occurrence: Conflicting Duties, 15 METAPhilosophy 77 (1984); Bennett, Whatever The Consequences, 26 ANALysis 83 (1966); Brand, The Language of Not Doing, 8 AM. PHIL. Q. 45 (1971) [hereinafter cited as Brand, The Language of Not Doing]; Brand, On von Wright's Logic of Action, 20 PhIL. Stud. 88 (1969); Danto, Freedom and Forbearance, in FreEdom AND Determinism 45 (K. Lehrer ed. 1966); Deutscher, Some Recollections of Ryle and Remarks on His Notion of Negative Action, 60 Australasian J. Phil. 254 (1982); Fitzgerald, Acting and Refraining, 27 Analysis 133 (1967); Gorr, Omissions, 28 Tul. Stud. Phil. 93 (1979) [hereinafter cited as Omissions]; Green, Killing and Letting Die, 17 Aм. PнiL. Q. 195 (1980) [hereinafter cited as Green, Killing and Letting Die]; Green, Refraining and Responsibility, 28 TuL. STUD. PHIL. 103 (1979) [hereinafter cited as Green, Refraining and Responsibility]; Harris, The Marxist Conception of Violence, 3 Phil. \& PUB. Aff. 192 (1974); Husak, Omissions, Causation and Liability, 30 PhIL. Q. 318 (1980); Lee, Omissions, 16 S. J. Phil. 339 (1978); Lichtenberg, The Moral Equivalence of Action and Omission, in New Essays in Ethics and Public Policy 19 (K. Nielsen \& S. Patten, eds. 1982); Mack, Causing and Failing to Prevent, Sw. J. PHIL. 83 (1976); Milanich, Allowing, Refraining, and Failing: The Structure of Omissions, 45 PHIL. STud. 57 (1984) [hereinafter cited as Milanich, Allowing, Refraining]; Moore, Refraining, 36 PhIL. Stud. 407 (1979); Morillo, Comments on Gorr and Green, 28 TUL. STUD. PhIL. 125 (1979); Morillo, Doing, Refraining, and the Strenuousness of Morality, 14 AM. PHIL. Q. 29 (1977) [hereinafter cited as Morillo, Doing, Refraining]; Ryle, Negative Actions, 115 Hermathena 81 (1973); Siegler, Omissions, 28 Analysis 98 (1968); Smith (formerly Milanich), The Concept of Allowing, 22 S. J. PHIL. 223 (1984); Smith (formerly Milanich) Ethics and Action Theory on Refraining: A Familiar Refrain in Two Parts, $20 \mathrm{~J}$. Value InQuiry 3 (1986) [hereinafter cited as Smith, Ethics and Action Theory]; Thomas, Acts, Omissions, and Common Sense Morality, in New Essays in Ethics and Public Policy 37 (K. Nielsen \& S. Patten eds. 1982); Walton, Omitting, Refraining and Letting Happen, 17 AM. PHIL. Q. 319 (1980) [hereinafter cited as Walton, Omitting, Refraining]; Walton, Omissions and Other Negative Actions, 1 Metamedicine 305 (1980); Weinryb, Omissions and Responsibility, 30 PHIL. Q. 1 (1980); Zimmerman, Taking Some of the Mystery Out of Omissions, 19 S. J. PHIL. 541 (1981); Hallmark, Negative Actions and Legal Liability (1984) (unpublished paper, available at the University of Arizona); Smith (formerly Milanich), Contemplating Failure: A Study of Unconscious Omission (1984) [hereinafter cited as Smith. Contemplating Failure] (unpublished paper, available at the University of Kentucky).

5. By "defensible," I mean sensitive to our existing linguistic and conceptual discriminations, without being bound to them. I would be amenable to refinement of this concept.

6. "Failure to act" is distinguishable from "failing to succeed." Brand appears to conflate them. See Brand, The Language of Not Doing, supra note 4, at 50-51. They are clearly distinguished in Smith, Contemplating Failure, supra note 4, at 6-9. 
(d) $a$ is in some other way morally required of $S .{ }^{7}$

As befits their generality, failures to act may be intentional or unintentional, avoidable or unavoidable.

But despite the generality of failures to act, they do not stand in relation to all other omissions as genus stands to species. In particular, $S$ 's refraining from doing $a$ need not constitute $S$ 's failure to do $a$. The person who refrains from taking an extra helping of dessert can hardly be said to have failed to do so. ${ }^{8}$ This realization, of course, is not to deny that some refrainings may also be characterized as failures: my refraining from going to someone's rescue may also be said to constitute my failure to attempt that person's rescue.

In respect of avoidability, the logic of failing to act differs significantly from that of refraining (in contradistinction to Brand $^{9}$ ), omitting (in contradistinction to D'Arcy ${ }^{10}$ ), and even, "letting happen." Failures to act need not be voluntary. In the case of refraining, omitting, and letting happen, however, voluntariness is implicated. $S$ 's failure to keep an appointment may result from an unexpected accident in which $S$ has been involved. ${ }^{11}$ It is the lack of ability that makes it inappropriate to say that $S$ refrained from keeping or omitted to keep the appointment. Likewise, if some harm occurs as a result of $S$ 's failure to keep the appointment, it is usually inappropriate to say that $S$ let it happen. To say that one had no alternative but to let $a$ happen is normally to offer a justification, not an excuse.

7. This characterization is a somewhat truncated version of the "reasonable expectation" condition given by Feinberg in J. FeinberG, supra note 4, at 161. For present purposes, the distinction between "obligation," "responsibility," and "moral requirements of other kinds" is not important. Milanich substitutes for (2) the disjunction:

(ii) $S$ has an express duty to do $a$; or

(iii) it is reasonable to expect $S$ to do $a$; or

(iv) $S$ refrains from doing $a$.

Milanich, Allowing, Refraining, supra note 4, at 64.

Condition (iv) creates some awkwardness. As I go on to note, the person who refrains from taking an extra helping of dessert can hardly be said to have failed to do so. See infra text accompanying note 8. Milanich is not oblivious to this observation, for she claims that it is most appropriate to speak of failure to act in cases where (ii) or (iii) are satisfied. Id. at 64-65. Nevertheless, she is prepared to say that "conscious failing is refraining". Id. In Smith, Contemplating Failure, supra note 4, at 3, a slightly different account is provided. There, for condition (2), she has: (ii) $S$ refrains from doing $a$, or it is reasonable to expect $S$ to do $a$, or both. But this proposition does not avoid the awkwardness to which I have referred. I would want to suggest that it is only where there is a reasonable expectation that $S$ does $a$, that $S$ 's refraining from doing $a$ constitutes a failure to act. If I am right, this enables us to drop any reference to refraining.

8. Nor, with all due respect to Milanich, Allowing, Refraining, supra note 4, at 65 , does the person who knowingly ("consciously") fails to do $a$ necessarily refrain from doing it. The person who knowingly fails to keep an appointment because he is immobilized by an accident does not refrain from keeping the appointment.

9. See Brand, The Language of Not Doing, supra note 4, at 47.

10. See E. D'Arcy, supra note 4, at 45.

11. James Hallmark has suggested to me that we do not "reasonably expect" people who are in accidents to keep their appointments. Letter from James Hallmark (Jan. 1985) (commenting on a draft of this article). I agree with this statement, but it bears upon the excusability of the failure, not on the appropriateness of speaking of the person's nonappearance as a failure. 
Most terms of omission refer to voluntary nondoing. These voluntary nondoings may be intended or unintended. Intended omissions are generally indicated by the term "refrain." We may say that

$S$ refrains from doing $a$ if and only if:

(1) $S$ consciously does not do $a$;

(2) $S$ has the opportunity to do $a$;

(3) $S$ has the ability to do $a ; 1^{12}$ and

(4) $S$ has some reason to do $a$, because

(a) $S$ has an inclination to do $a$; or because

(b) $S$ recognizes a responsibility, obligation, or some other requirement to do a. 13

Unintended omissions are most frequently indicated by the term "omit," though something may be intentionally as well as unintentionally omitted. ${ }^{14}$ We may say that

$S$ omitted to do $a$ if and only if:

(1) $S$ did not do $a$;

(2) $S$ had the opportunity to do $a$;

(3) $S$ had the ability to do $a$;

(4) $S$ had good reason to believe that he had the opportunity and ability to do $a$; and

(5) $a$ was reasonably expected of $S$, because

(a) $S$, or those in $S$ 's position, ordinarily do $a$; or

(b) $S$ had a responsibility to do $a$; or

(c) $S$ was obligated to do $a$; or

(d) $a$ was in some other way morally required of $S$.

In proffering this analysis of "omit," I have used "omitted" in order to avoid complicating the analysis with temporal factors. For, at the time when $S$ omits to do $a$, he may lack the ability or the opportunity to do it. $S$ may

12. See Milanich, Allowing, Refraining, supra note 4, at 65, who claims that refraining does not require anything as strong as conditions (2) and (3); it is enough if $S$ (reasonably?) believes that he has the opportunity and ability to do $a$. But if all that is required is $S$ 's belief, we should speak instead of $S$ refraining from attempting to do $a$.

Some writers have wished to add a further condition, namely, that $S$ is aware that he has the opportunity and ability to do $a$. See Green, Killing and Letting Die, supra note 4, at 198. There is something to be said for this condition. If $S$ believes wrongly that he does not have the opportunity or ability to do $a$, and for that reason does not attempt to do it, we are more likely to say that " $S$ refrained from attempting to do $a$ " than " $S$ refrained from doing $a$ " (even though $S$ would have succeeded had $a$ been attempted). Still, the requirement that $S$ be aware rather than not disbelieve that he has the opportunity and ability to do $a$ seems too strong.

13. Condition (4) has been a source of some difficulty. Some have omitted it altogether. E.g., Brand, The Language of Not Doing, supra note 4 , at 49 . The condition looks very strained where what is supposedly refrained from is strongly disliked. For example, the person with a strong aversion to oysters is not usually said to refrain from eating them when invited to do so. But attempts to rectify the problem have often been expressed too strongly. Gorr speaks of the need for a "desire" to do $a$. Gorr, Omissions, supra note 4, at 95-96. Others have favored the term "inclination." Milanich has a more complicated formulation: $S$ is inclined to do $a$; or $a$ is the natural response to an offer or invitation that $S$ declines. Milanich, Allowing, Refraining, supra note 4 , at 65 .

But there may be neither where one refrains from doing what one recognizes as a duty to do but has no inclination to do. Smith, Ethics and Action Theory, supra note 4, at 8, makes this modification: $S$ is inclined to do $a$; or doing $a$ is brought to $S$ 's attention. But this formulation now seems too weak.

14. Refraining is conscious in a way that omitting need not be. If I refrain from keeping an appointment, my not keeping it must be conscious. I may, however, omit to keep it by forgetting about it or sleeping late. Feinberg's account of refraining has $S$ "declining" to act. He sees omitting as a species of refraining. J. FeinberG, supra note 4 , at 258 n.34. Other writers have argued that "conscious omission" is identical to refraining, but that will not be so unless condition (5) is satisfied. 
culpably disable or distance himself from doing $a$. If $S$, a lifeguard on duty, deserts his post or drinks to excess so that he lacks either the opportunity or ability to attempt $T$ 's rescue, his lack of opportunity or ability will not dissuade us from saying that he omitted to attempt $T$ 's rescue. He once had the requisite opportunity and ability, but lost it by acting in a manner contrary to what was reasonably expected of him.

This temporal dissociation of opportunity and ability from the occurrence of $S$ 's omission creates barriers to an all-encompassing analysis. But it also provides an insight into the normative character of most uses of omissive terms. Contrary to reasonable expectations, it would not have been appropriate to say that $S$ omitted to do $a$ had the opportunity or ability to do $a$ been lost involuntarily.

Use of the past tense also helps in the formulation of condition (4). If the reason for $S$ omitting to do $a$ is that he forgets to do it, do we want to say that he has good reason to believe that he has the opportunity and ability to do $a$ ? Even if we do, condition (4) may seem too narrow. If Charles, a lifeguard, omits to rescue Fred because he has fallen asleep, it is not correct to say that Charles ever had good reason to believe that he had the opportunity and ability to rescue Fred, although it is reasonable to suggest that Charles had good reason to believe he had the opportunity and ability to rescue anyone needing such assistance.

The language of letting happen suggests that consequences attend omissions. ${ }^{15}$ We may say that

$S$ lets $a$ happen if and only if:

(1) There is a chain of events in which $a$ will come about unless some intervening factor prevents $a$; 16

(2) $S$ fails to intervene to prevent $a ; 17$

(3) $S$ has the opportunity to prevent $a$;

15. Milanich speaks of letting happen as a second-order concept because what is "let happen" is accomplished by not doing-or doing-something else. Milanich, Allowing, Refraining, supra note 4, at 58. Helen Freeman, following J.L. Austin, felicitously coins the term "perficience," to characterize those doings in which an outcome is implied. On her account, perficiences have the form: By doing $b, S$ was $a$ ing $T$, (where $S$ and $T$ are persons, $a$ is the perficient verb (which she distinguishes from an "activity verb"), and some condition in $T$ is the perficient outcome). She writes: "The criterion for judging the truth or falsity of a perficience claim is whether or not the outcome implied in $[T]$ has been brought about through [S's] actions," Freeman, The Concept of Teaching, in ProceEdings PHIL. Educ. Soc'y Gr. Brit. 7, 18 (1973). Among perficient verbs she includes "hurt," "offend," "interrupt," "humiliate," "frighten," "kill," and "inspire." Her account of perficiences is not specially geared to omissions, but it might easily be amended to allow for them, and to include "let happen" in the catalogue.

16. Some writers have wanted to argue that the causal chain leading to $a$ must be such that it was not initiated by $S$. E.g., Hallmark, supra note 4, at 11 . There is some point to this argument, but it is too strong. A shot fired by Arthur while hunting, ricochets off a rock and grazes Bill's head. Bill is temporarily stunned, and falls face down into a puddle of water. Arthur sees Bill fall, but leaves him there. If Bill drowns, we are likely to say that Arthur let him drown, even though Arthur "initiated" the chain of causes that led to Bill's death. Similarly, if I turn on the tap in the bath, knowing that I must turn it off, but then forget to do so, I might be said to have let the house flood. Cf. Commonwealth v. Cali, 247 Mass. 20, 141 N.E. 510 (1923).

17. Condition (2) has occasioned some discussion. Green, Refraining and Responsibility, supra note 4 , at 107, uses the more restrictive "refrain," and Hallmark allows for either "refrain" or "omit." Hallmark, supra note 4 , at 16 . The more encompassing "fails" does better justice to the range of 
(4) $S$ has the ability to prevent $a$;

(5) $S$ knows that $a$ is likely to happen if he fails to prevent $a$; and

(6) $a$ happens. ${ }^{18}$

I have characterized letting happen as contributing to an outcome by means of an avoidable failure to intervene, but this characterization may be too simple. Letting happen may not be a failure to intervene, but rather a failure to continue, to prevent $a$. Suppose a person is being sustained by a respirator. I turn the respirator off so that the support is removed and the person dies. What $\mathrm{I}$ have done is not adequately characterized as a failure to intervene. But have I not let the person die? It depends on the circumstances. If the respirator is simply prolonging the dying process, then my turning it off may be characterizable as letting the person die. But if use of the respirator is seen as a temporary measure, an interim device to enable the person's survival until his own functions are restored, then turning off the respirator may be seen not simply as letting him die, but as killing him.

On the basis of these analyses, it is not clear that it is useful to speak of the terms involved as being normative or nonnormative (though particular locutions in which they occur may be). ${ }^{19}$ The "reasonable expectations" condition, common to "fail," "omit," and "let happen," may refer to either a statistical or normative expectation. Likewise, in the case of "refrain," the reasons that constitute a particular nondoing as refraining may be grounded in normative or nonnormative considerations.

Although I have suggested that the language of omission and our interest in ascribing responsibility are closely related, I do not wish to imply that the person who omits to do $a$ is ipso facto blameworthy. The reason is not simply because reasonable expectations need not be normatively grounded, but also because even those that are may be outweighed by other, more significant expectations. The person who omits to do $a$ is someone who has acted voluntarily, or whose omission is the result of a voluntary action. Responsibility is a distinct question, and blameworthiness yet another question.

\section{III}

\section{The Ontological Status of Omissions}

What is the ontological status of omissions? Are they mere absencesnondoings simpliciter, having no "real" existence? Is the attempt to give some sort of behavioral standing to omissions like the bizarre attempt to make a something out of "nothing"-the reification of a substantive? That has

nondoings appropriate to "letting happen." Milanich suggests that the intervention that $S$ fails to execute may take the form of either a positive or negative act.

18. If condition (6) is omitted, we are able to make a rough distinction between letting $a$ happen and leaving $a$ to happen.

19. Brand, The Language of Not Doing, supra note 4, at 45, speaks of "locutions," but tends to focus on "terms," seeing some as normative and others as nonnormative. Gorr, supra note 4, at 9394, considers it important that a nonnormative account of omissions be provided. However, I am not persuaded that he has provided any convincing reasons for this position. 
certainly been the view of some writers. Early in the century, Stroud wrote that "an omission is not like an act, a real event, but is merely an artificial conception consisting of the negation of a particular act."20 And Michael Gorr has recently written:

To omit (or refrain from) preventing some event from occurring is not to perform some metaphysically mysterious 'negative' action .... Rather, it is simply not to have acted to prevent that event in circumstances where one had the ability and opportunity to have so acted. Consequently, it is a serious mistake to think of omitting as a special kind of doing, because a doing is an event, i.e., something that happens. ${ }^{21}$

Such remarks express a widely held position, stated and defended with varying degrees of sophistication. ${ }^{22}$ Omissions are seen as somehow "nonsubstantial," "factually hollow"-mere intellectual constructs-not the sort of thing one can put his finger on or to which one can point.

Nevertheless, such a view betrays, or at least suggests, three misunderstandings: (1) it conflates radically different kinds of nondoings; (2) it confuses the failure to do $a$ with a failure to act; and (3) it conflates acts with actions. I will discuss each of these misunderstandings in turn.

(1) If $S$ fails to do $a$, then $S$ does not do $a$. It does not follow, however, that if $S$ does not do $a$, then $S$ has failed to do $a$. Failures to act, and omissions generally, make up only a tiny proportion of those things that we may be said not to do. Furthermore, with all due respect to Gorr, they comprise only a small proportion of those things that, though we have both the opportunity and ability, we do not do. ${ }^{23}$

For example, at the time I write this article, I am not hunting game in Africa, drinking beer in an Icelandic pub, speaking Hungarian, taking a sauna in a health club, or exploring craters on the other side of the moon. To do some of these things I have neither the opportunity nor the ability; to do some I have the opportunity but not the ability; and to do some I have the ability but not the opportunity. My not doing them does not constitute an omission or failure on my part. I am not in any way engaged in not doing these things. However, lest it be thought that my failure to do these things is simply a function of my lack of opportunity or ability, it is equally true that I am not at present eating an ice cream, cutting my toenails or working at a crossword puzzle, even though I do have the opportunity and ability to do any of them. Yet, even my failure to do these things, it so happens, does not constitute an omission on my part. ${ }^{24}$ There are myriad things that I am not doing, and the

20. A. Stroud, Mens Rea: Or, Imputability Under the Law of England 4 (1914).

21. Gorr, Positive and Negative Natural Duties (1984) (unpublished manuscript, summarizing his position in Gorr, Omissions, supra note 4).

22. Among the sophisticated versions, I would include Ryle and Thomson. Ryle sees the "at first puzzling, unconcreteness, i.e., the factual, circumstantial and behavioural hollowness of our negative 'actions' ... [as] a special case of the factual hollowness of denials of existence, occurrence or performance, etc. in general." Ryle, supra note 4, at 89 . Yet he still wants to distinguish them from mere nondoings.

23. Gorr, Omissions, supra note 4 , at 97 .

24. In a personal communication, Gorr has argued that "there is nothing linguistically improper" about saying that I am at present omitting to eat an ice cream, given that I have the 
fact that I am not doing them is, as Ryle once remarked, "no more interesting than the fact that whatever the date may be today, there are infinitely many other dates that it is not; or the fact that wherever the snowflake did fall, there are infinitely many other places where it did not fall."25

If sleeping Richard in Sydney does not rescue drowning Fred from the New York Central Park Pond, he is not rescuing in a very different respect than unencumbered superswimmer Charles who watches Fred drown just a few yards away. Only Charles omits to rescue Fred. Only Charles lets Fred drown. But not even Charles omits to rescue Fred or lets him drown if he, like Richard, is asleep, assuming Charles is not responsible for watching over the pond. What constitutes a lack of ability or opportunity, then, may depend on what can reasonably be expected of the nondoer.

Omissions constitute a relatively restricted subclass of nondoings. There is an attribution element to omissions that other nondoings do not possess. Although it can truly be said that I am not hunting game in Africa or eating an ice cream, it is difficult to understand what point there is in saying that $I$, rather than somebody else, am not doing these things. These nondoings are simply free-floating act(ivity) descriptions, and their attachment to me seems entirely fortuitous. It is equally difficult to understand why it is said that Richard did not rescue Fred, and not that Prince Charles or Henry Kissinger or Sophia Loren or some isolated Eskimo did not rescue him. Omissions are attached to omitters in a way that mere nondoings are not.

What is it that attaches them to me? In the case of failing, omitting, and letting happen, there must be a reasonable expectation that $S$ would have done what was omitted or let happen. In the case of refraining, the emphasis is on $S$ 's "having a reason" to do $a$. What creates these reasonable expectations? The simple answer, at least in the case of failing, omitting, and letting happen, is that they are conventional manifestations of a social milieu in which something like Wittgensteinian "forms of life" are able to get a grip. Omissions are the offspring of social life, in which there is a certain coordination of behavior, and sharing of concepts and values. In speaking of such expectations as conventional, I do not intend to denigrate them. Conventions are of different kinds, and it is an injustice to their variety if we seek to place them all in a single model. Certainly, it is unjust to consider them as "merely arbitrary." It is probable that many of the conventions that inform our expectations originally arose out of beliefs about the operations of nature or the demands of social existence, although in some cases these beliefs have been lost, and the expectations now float freely, as might an arbitrary (though not "merely arbitrary") convention. Others, particularly

opportunity and ability to do so. At most, it is "pointless and silly"-like saying "I weigh less than 5000 pounds." Letter from Michael Gore (Jan. 1985). However, I do not think the cases are analogous. In the case of nondoing, there are preferred alternative ways of making the point. It would not only be pointless but also misleading to say that I am at present omitting to eat an ice cream. It would be misleading, and not simply pointless, precisely because of the "reasonable expectations" condition.

25. Ryle, supra note 4 , at 81 . 
those with a significant moral content, tend to demand from us a raison d'être if they are to retain their practical authority (their normative status).

Given that we expect those in certain roles and relations to render assistance to the needy, why do we not also expect assistance to be rendered, to the extent of promulgating an enforceable rule, in those cases where there is no preexisting role or consensual relationship? It is not an unreasonable base expectation that people should render easy aid, though the foundations of such an expectation are disputed. ${ }^{26}$ The notion that it is reasonable to enforce that expectation, however, is less widely accepted. Can rendering assistance be seen as part of that core of moral beliefs to which conformity may be compelled, or would any such requirement represent an unacceptable invasion of individual liberty? We consider it justifiable to interfere with those who use their liberty to assault, defraud, and default. Liberty thus used does not merely upset, but violates, the reasonable expectations of others. At first blush, it may not appear that we can make this statement about the person who fails to render easy aid. In most cases, the bystander will not have initiated the imperilling situation or created expectations on which the imperilled person would have placed reliance. The bystander's presence is entirely fortuitous. Even though the bystander would sacrifice only a small measure of liberty, and in the circumstances could reasonably be expected to do so, one might argue that the requirement to render such easy aid violates the bystander's autonomy by sacrificing one person's right to another's need. I am not convinced, however, that the bystander's failure is as innocuous as this statement suggests. In my view, the failure to render easy aid to the gravely imperilled is not merely a failure to benefit. ${ }^{27}$

(2) If $S$ omits or fails to do $a$, then $S$ does not do $a$. Both Stroud and Gorr take this fact to imply that $S$ does nothing at all. ${ }^{28}$ This conclusion does not follow. Attributions of omission are generally specific. Some relatively determinate course of action, $a$, is said to have been omitted. It does not follow that $S$ has omitted to act altogether. It is only if the latter can be inferred that omissions can be construed as mere negations, as absences, or nothings.

26. For two recent discussions, see Herman, Mutual Aid and Respect for Persons, 94 ETHICs 577 (1984); Wallace, The Duty to Help People in Distress, 29 ANALysis 33 (1968). Given the argument that I later advance about the causal status of omissions, see infra section IV, it is not open to me to base (as I was once tempted) the moral requirement to aid on its causal impact. If, as some moral libertarians might claim (for example, followers of Ayn Rand), that expectation is morally illegitimate, then the case for according a causal role to not aiding is undermined.

27. See J. FeInberg, supra note 4, at $130-43$. In section IV, I shall suggest that if we are prepared to concede that the person who does not render easy aid fails to do so, or lets happen the harm which the nonaided party suffers, then that person's inaction is an essential factor in the occurrence or perpetuation of the harm. Omissions properly figure in explanations of why certain harms occur (or are as bad as they are). Therefore, it is reasonable to expect that easy aid be required.

28. A. STroud, supra note 20 , at 4 . Gorr does not actually make this statement. He does not wish to argue that the person who omits to do $a$ is motionless or inactive. But he wishes to dissociate fairly radically what the person is doing when he omits to do $a$ from the omitting of $a$. It is not clear that he would want to allow the propriety of "in doing $b, S$ omitted to do $a$," for that would give too active a status to $S$ 's omitting to do $a$. 
It is true that omitting to do some determinate action does not itself specify a determinate action, not if we focus, as action theorists tend to do, on particular bodily configurations. Ryle speaks of omissions as "higher order operations upon lower order positive actions[,]"29 where the focus is not primarily on the characterization of a specific bodily configuration but on "lines of action," in which, in my view, certain reasonable expectations remain unrealized. These higher order operations are no less genuine components in a person's conduct than the lower order actions in which they are anchored. It is just that they are not constituted by or manifested in terms of some relatively fixed behavioral configuration. Lurking behind Ryle's introduction of this higher order/lower order terminology is his longstanding desire to exorcise the ghosts from the machine, an unwillingness to give any nonbehavioral status to the mental processes that are necessary to the characterization of such conscious omissions as refraining and postponing. ${ }^{30}$ The fact that "behavioralizing" omissions has a special significance for Ryle, however, does not gainsay the usefulness of the terminology. Higher order acts stand to lower order acts as furniture stands to tables and chairs. Just as we need to refer to various social conventions in order to see how a diversity of artifacts can comprise furniture, so too we need to appeal to a range of social expectations in order to see how various courses of action constitute omissions.

In contradistinction to Brand, ${ }^{31}$ however, in order to make this point, and to allow for omissions to constitute "something" rather than "nothing," we do not need to construe $b$ as a doing of something else, in order not to do $a$. We may do something else, $b$, in order to aid us in our negative act of not doing $a$, though $b$ need not take the form of a bodily movement. We need not, however, do something else. The person who refrains from taking a second helping of dessert need do no more than reflect on his wider goals in order for not taking a second helping to constitute refraining. Some positive action or bodily movement designed to ensure that $a$ not happen need not exist.

(3) One common reason for denying act status to omissions is because they lack characteristic bodily expression. That is understood in at least two ways:

(a) There is a complete absence of any visible bodily movement. If $S$ omits to rescue $T$, this omission might be expressed by $S$ 's being asleep or looking on impassively-"not moving a muscle," as we might say. However, it should be noted that not moving a muscle may sometimes require a great deal of "voluntary muscular contraction" (Cf. Holmes' definition of the actus reus ${ }^{32}$ ). For example, voluntary muscle contraction is required when one stands at attention during an inspection parade or poses for a photograph.

29. Ryle, supra note 4 , at 88 .

30. Max Deutscher points out that Ryle's aversion to such "inner goings-on" frequently jeopardizes his attempt to distinguish omissions from mere nondoings. Deutscher, supra note 4 , at 257-58, 260. Deutscher himself, however, tends to focus too narrowly on intentional nondoings.

31. Brand, The Language of Not Doing, supra note 4, at 49. Ryle also sometimes edges toward this position in his desire to avoid interiorizing such acts. Ryle, supra note 4, at 87-90.

32. O. Holmes, The Common Law 54 (1963). 
(b) Something is done other than what one omitted to do (say, watching television instead of marking papers). Where one does something else instead, there does not seem to be much limit on the "something else." I may have omitted to mark papers because I watched television, but it is equally possible that I went out, had a bath, or went to bed. There does not seem to be any way of physically characterizing the omission. ${ }^{33}$

Lurking behind these objections to the act status of omissions is a conflation of act with action, or at least a belief that acts constitute a subclass of actions. Many writers use the concepts interchangeably, and focus on actions when characterizing these concepts. ${ }^{34}$ There is some reason to think that actions necessarily manifest themselves in bodily movement (usually bodily movements of a reasonably determinate kind $^{35}$ ). Indeed, so central to our concept of action is visible movement that we sometimes speak in an extended sense of the action of inanimate objects (for example, the action of a watch mechanism). Generally, however, actions are attributable only to persons, and in that context there is a longstanding debate about the ways in which actions are distinguishable from mere bodily movements. It is precisely because actions are manifested in bodily movements that the debate arises. Given the conflation of acts with actions and the focus on the latter, it is not surprising that the absence of some determinate bodily movement from omissions is taken as evidence of their fictional or unreal status. But although bodily motion appears to be essential to our concept of action, it is not obviously essential to our concept of an act. It is true that acts display themselves in physical movement, and some acts may require reference to physical movement for their characterization (in which case they may also be characterizable as actions). But their embodiment in a relatively determinate set of physical movements does not seem to be essential. This phenomenon, of course, may create epistemological problems: sometimes it will be very difficult to determine whether someone is acting, or acting in a particular way. Although such epistemological problems are not separable from the ontological question, they should not be confused with it.

We speak correctly and without awkwardness, of mental acts or act-kindsdeliberating, reflecting, resolving, calculating, meditating, and so on-without requiring that these be understood as, or be reducible to, publicly witnessable bodily movements. We speak this way even if we wish to argue that the presence or absence of certain kinds of bodily motion, including speech acts, constitutes evidence for or against the truth of claims in which such mental acts are being or have been engaged. We further allow that such acts may

33. Ryle, somewhat captivated by the negativeness of negative acts, suggests that there is no limit to the number of negative acts that a person may be performing during a particular temporal stretch. Ryle, supra note 4 , at 84 . Such a state of affairs is doubtful, and again symptomatizes Ryle's tendency to slip back into a position where omissions are virtually indistinguishable from mere nondoings.

34. See, e.g., E. D'Arcy, Human Acts: An Essay in Their Moral Evaluation (1963).

35. In speaking of actions as involving bodily movements of a reasonably determinate kind, I have in mind the fact that we often identify actions via particular constellations of bodily movements (for example, spanking a child). Where there is no such determinateness (for example, punishment), we are more inclined to speak of the phenomenon as an activity or course of action. 
figure in explanations of behavior, as exercising a significant causal role. Yet we do not speak similarly of mental actions. Such characterization would tie mental actions to bodily movements in a quite misleading manner. It would give them a shape that they do not possess.

We can speak with no more awkwardness, I believe, of omissions as acts. The mere fact that omissions may require no determinate bodily movement does not disqualify them being acts. In some cases they may be intentional, as when a person refrains from doing something. In other cases, they are unintentional. Where they are unintentional, it is often thought that there is a problem of mens rea (in addition to the problem of an actus reus). But the possession of a mens rea need not be thought of in terms of specific intent. As Hart has argued in relation to negligent acts, the requirements of mens rea are met by establishing that the person was capable of conforming to what was expected of him. ${ }^{36}$ Likewise, the person guilty of an omission may be said to have possessed the requisite mens rea if he failed to act in circumstances in which he had the ability to do so in a manner that could be reasonably expected of him.

Thus, if we distinguish acts from actions, and see actions as a subclass of acts rather than vice versa, we may not be mesmerized by the negativity of omissions into seeing them as mere absences. Instead, we will seek to understand human behavior not in terms of this or that relatively determinate set of bodily movements, or some construct out of them, but first and foremost by reference to a wider background of individual purposes and social expectations. These purposes and expectations, and not the bodily movements, will then become the touchstone of our understanding.

I suspect that it is because of the rather different emphases implicit in our concepts of act and action that when we consider the appropriate object of criminal liability, we neither use the term "act" nor "action," but instead prefer the term "conduct." I suspect a preference for the use of this term because conduct, like action, requires some sort of externalization. An act of deliberation does not, as such, constitute conduct. Such acts are, in more than one sense, private. But conduct does not require the kind of externalization that is central to action (namely, bodily movement), for a person's omissions may be included in an inventory of his conduct even though such conduct does not correspond to bodily motion of a determinate kind. Conduct, to use the standard jargon, may be positive or negative. It may be given its shape by positive bodily movements of a particular kind, and thus be considered an action. Alternatively, it may lack such shaping, and instead be expressed via the dashing of certain kinds of expectations. An act it will be, and one that is public. Thus, in certain circumstances, it will be of direct interest to the legislator. Yet it will not typically or necessarily manifest itself through some determinate bodily movement.

36. H.L.A. HART, Negligence, Mens Rea and Criminal Responsibility, in Punishment and RESPONSIBILITY 136 (1968). 
In a somewhat neglected article, Frederick Siegler makes the suggestive point that we speak of acts of love, mercy, vengeance, and courage, rather than actions of the same, since these acts can be performed in the absence of bodily motion: "not criticizing a child for a wrong (love), not killing an enemy (mercy), letting a foe drown (vengeance), not telling secrets (courage)."37 Despite the negative form of these acts and the absence of bodily movement in their performance, such acts may be deemed to constitute conduct for the purposes of the law.

In sum, it is necessary to distinguish different kinds of nondoings. In one sense, omissions are nondoings because they involve not doing something that there was reason to do or was reasonably expected. In another sense, however, omissions are things that we do. Though their lack of reference to bodily movement of a reasonably determinate kind renders it inappropriate to speak of omissions as actions, it does not gainsay their act or conduct status.

\section{Omissions as Causal factors in Particular Outcomes}

It is one thing to say that omissions are not only characterizable as acts but also have the status of conduct. It is another to claim that they constitute conduct for which a person may be held criminally liable. Normally, a person is not held to be criminally liable for his conduct unless that conduct violates another's rights. That is, it is punishable only if it wrongfully impairs or endangers another's welfare interests. ${ }^{38}$ There must be some link between that person's conduct and the harm suffered or risked by another, so that the other's harm or endangerment can be attributed in whole or part to the former's conduct. This link is usually seen as an issue of causation: there must be at least some causal connection between the harm suffered or risked and another's wrongdoing for the wrongdoer to be held liable for that harm or endangerment. Even in the case of positive acts, however, such an insistence is problematic because the general issue of causation is problematic. The problem is compounded in the case of omissions. Whereas it is plausible to see positive acts as causally potent, as bringing about certain consequences, it is easy to think that omissions, whatever their status, do not play a causal role in any harmful outcome with which they are associated. For what $S$ fails to do or refrains from doing is to intervene in some harm-causing or harmthreatening chain of events.

To engage in any general discussion of causation here would plunge too deeply into problems that are not specific enough to the issue of omissions. The only general remark pertinent here is that many of those who want to deny causal status to omissions operate within a model of causation that has its home in "scientific rationality" rather than the discourse appropriate to

37. Siegler, supra note 4 , at 106 .

38. For a partial defense of this way of putting it, see Kleinig, Crime and Concept of Harm, 15 AM. PhrL. Q. 25 (1978). 
human interaction. It is perhaps because of the preoccupation with "actions" and, in particular, the bodily movements that embody them that mechanistic models of causation have seemed appropriate. But it is important to remember that the debate surrounding causation antedated by many centuries the refined and technicized understandings that emerged from the scientific revolution. It may be inappropriate to provide a causal explanation of an engine's operation by including among its causal conditions normatively impregnated data. There is a great deal of human conduct, however, that cannot be properly understood without recourse to explanatory factors that are normatively inscribed.

In the legal context, it is a common argument that if a person is to be held criminally liable for some harm to or endangerment of others, his wrongful conduct must have figured in the bringing about of that harm (that is, it must have been a causal factor), and it must have been proximate to that harm (that is, it must have played a substantial role in its coming about). The satisfaction of each of these conditions has proved problematic. The first has often been determined by a consideration whether, had it not been for the conduct in question, the harm or endangerment would have occurred. The second has tended to require a joint consideration of policy and statistical factors; that is, it has required a resort to ambiguously conceived expectations. ${ }^{39}$

The determination of causal factors by reference to some conduct's material sine qua non status, although initially attractive, is fraught with difficulties. Is it really helpful to say that the 1846 famine in Saxony was a causal factor in Charles' failure to rescue Fred, since, had it not been for that famine, Charles' great-great-grandparents would not have migrated to the United States, and so forth? One might just as well argue that anti-Semitism in Europe during the 1930's was a causal factor in Fred's drowning, since had it not been for anti-Semitism, Fred's father would not have come to the United States, met Fred's mother, and so forth. An unconstrained conditio sine qua non theory is bound to overburden us unhelpfully with causal factors. But not only is it too encompassing, it is also too narrow because events are frequently overdetermined. There are many situations in which factors that we would wish to see as causally implicated in some harm or endangerment, at least for moral and legal purposes, are nevertheless not essential to its coming about.

It is not easy to provide a more satisfactory way of separating out causally relevant factors, and perhaps it is wrong to expect discovery of some decisive means of so doing. Determination of causally relevant factors may depend to an extent on contextual factors-the background and interests of the inquirer-as much as on the intricacies of a causal history. The problem with citing the 1846 famine as a causal factor in Charles' failure to rescue Fred is

39. It has been suggested to me that these two factors are better seen as dialectically related: although both may be satisfied, greater weight falls on one as the other becomes less plausible or more difficult to establish. If so, this relationship will take some of the bite out of the objections considered below. See infra pp. 175-78. 
that, for almost any purpose that we might have in seeking to provide a causal history of the failure, the famine would be too remote and too insignificant to be mentioned. It does so little to help the inquirer understand why this outcome rather than some other came about. And in cases of causal overdetermination, particular factors, though inessential, may have been sufficient to produce a particular result. Perhaps we should view causal factors as those that, when taken together, are sufficient to explain the coming about of some event, and not insist that some fixed or exclusive group of such factors explain it. ${ }^{40}$

Feinberg helpfully recasts the issue of proximity as one of selecting from the various causal factors one or more factors that can be called the cause. This issue is even more obviously bound up with contextual factors, both conventional and individual, than the issue of causation. ${ }^{41}$ What is cited or nominated as the cause depends crucially on certain broad interests that are represented in causal inquiries and, within those interests, on the background and interests of the particular inquirer. Feinberg distinguishes interests in explanation, regulation, and responsibility-fixation, each of which may generate its own causal citation. In explanatory contexts, our interest is in increasing our understanding, in illuminating what we find obscure. The cause cited will be the causal factor or factors that gives us the light we, individually or collectively, need. In regulatory contexts, our interest is in "getting a handle on" some portion of our world so that we may manipulate it. What we cite as the cause will be the causal factor(s) that gives us the best possibility of controlling the events in question-whether to counter, maintain, or replicate them, or to prevent any future occurrence. In responsibility-fixing contexts, which are generally limited to circumstances in which human interests have been impaired or are threatened with impairment, our interest is in determining whether anyone was at fault. Whom we cite as the cause is usually the prime candidate for blame.

Is it plausible to argue that omissions, no less than positive acts, can figure in outcomes in a causally significant way? Can Charles' failure to go to Fred's aid be included in the causal factors surrounding his death? Would it be possible to go even further, and to argue that Charles was the cause of Fred's death? On an unmodified sine qua non theory, it might seem implausible to give Charles' failure to act any causal role in Fred's demise. After all, had Charles not been present, Fred would still have drowned. Charles' fortuitous presence, presuming he does not persuade other possible rescuers to leave, seems to add nothing essential to the situation. Charles is witness to a conjunction of factors that is sufficient to bring about Fred's death; no contribution on his part is required. But, as discussed above, ${ }^{42}$ an unmodified sine qua non theory falters in the context of issues like causal

40. See, e.g., H.L.A. Hart \& A. Honoré, Causation in the Law 171-87, 292-322 (1959).

41. This analysis is most helpfully developed in his essay, Sua Culpa, in J. FeinberG, DoIng AND Deserving: Essays in the Theory of Responsibility 187, 202-07 (1970).

42. See supra pp. 175-76. 
overdetermination. And it is at least arguable that causal overdetermination is present in this example. The conjunction of factors has led to Fred's desperate plight and Charles' failure to act. That Charles' omission was not necessary does not show that it was not a causal factor, or in the circumstances, insufficient. Perhaps this point can be made more strongly. We should not assume, as does the critic of Charles' causal role, that we can decide whether Charles' failure to act was causally relevant by determining what would have happened had Charles not been there. For the situation is one in which Charles was there, and in that situation in which Charles might reasonably have been expected to attempt a rescue, he did not do so. So we would not say, " Fred would have drowned when he did anyway," but: "Had it not been for Charles' failure to act, Fred would have been rescued."

Whatever the capacity of a modified sine qua non theory to cope with failures to act, there are easier paths to the conclusion that failures to act can be causal factors. As discussed in section II, some omissive language is already causal in character. The language of letting happen and its cognates already bespeaks potent failure. When $S$ lets $a$ happen, then $a$ is causally linked to $S$ by $S$ 's omission. What $S$ fails to do is contributory to $a$. The language of letting happen, though not the only causal language appropriate to omissions, is the paradigmatically appropriate language.

How strong is such language? Can it be used to pick out the cause of some outcome? This question is tricky. In certain circumstances, the language of omission can be used to pick out the cause. If I forget to turn off the bathroom tap, so that the house floods, then my omission may be cited as the cause. If I put my child into the bath and refrain from helping him when he slips, then it may be said that I let him drown, and that my failure to assist when he slipped was the cause of his drowning. There are two reasons why it makes good sense to speak of the omission in these cases as the cause. The first is that I was responsible for initiating the causal chain leading to the untoward outcomes: I turned on the tap in the first place and I put the baby in the bath. ${ }^{43}$ But why not say then that the cause was my turning on the tap or placing the baby in the bath? The answer is evident in the second reason: under the circumstances, turning on the tap and putting the baby in the bath were wholly unexceptionable acts. They might have been done a hundred times before without any catastrophic outcome. Simply citing these acts gives little help to the person seeking illumination. What illuminates the situation are the facts that I forgot to turn the tap off and refrained from lending assistance, because they were the unexpected elements in the situation.

Most often, however, we do not cite omissions as the causes of the outcomes to which they are related. To cite them as the causes would suggest

43. The issue of initiation is not unproblematic. It lies, nevertheless, behind a distinction frequently made in legal contexts between misfeasance and nonfeasance. See Weinrib, supra note 1 , at $251-58$. 
too strongly that they were brought about rather than simply allowed to occur. ${ }^{\mathbf{4 4}}$ In general, omissions are "harm exacerbating" rather than "harminitiating." 45 The person who fails to act is at fault, although we may be reluctant, without additional information, to go so far as to say that the outcome was his fault. What Charles does (that is, fails to do) results in Fred's drowning, but it would be misleading to say either that he drowned him or caused him to drown. Charles is not relieved of all responsibility, but neither is it suggested that he created the perilous situation.

I am suggesting, then, that there is nothing about omissions as such that renders it inappropriate to include them in causal histories. They may not function as pulleys or levers, but they do constitute elements in situational complexes that can contribute to our understanding why a particular outcome occurred, or where something could have been other than it was, or whether anyone was at fault. Even though it may often be inappropriate to speak of the act omitted as the cause of the outcome to which it has contributed, calling its causal status into question is not a sufficient reason for downplaying its contribution.

The Necessity of Determining a Causal Link Between OMissions and OUtComes to IMPOSITION OF Criminal LIABILITY

There is an alternative strategy to the one taken in this article. Why, it might be asked, is anything as strong as a causal thesis required to hold people criminally liable for their failures to act? Douglas Husak, for instance, argues that the connection may be of a different kind. ${ }^{46}$ The lifesaver who fails to go to someone's rescue may be held liable, not because he was a causal factor in that person's drowning, but because, having some control over the outcome, he failed to act to prevent it. According to Husak, all that is needed to justify the introduction of good Samaritan requirements is a recognition that easy aid can reasonably be expected of people where others are believed or known to be gravely imperilled. It is the failure to do what one has a responsibility to do that justifies legislating against bad Samaritans. ${ }^{47}$ Husak contends that the attempt to subsume bad Samaritan acts under the harm principle as, perhaps, a further specification of existing homicide statutes conflates judicial with legislative activity. Because the argument for good samaritan requirements is almost always an argument for some new statutory initiative, and not for a reform of judicial interpretation:

44. I do not, however, wish to deny that one may bring about $x$ by allowing it to occur. For example, one may bring about his child's death by allowing the child to starve. There is a continuum of cases rather than a rigid division.

45. Kleinig, Good Samaritanism, 5 Phil. \& Pub. Aff. 382, 393-94 (1976). For reasons that will become clear in section V, I should also have included "risk-increasing."

46. Husak, supra note 4.

47. Letter from Douglas Husak to John Kleinig (Apr. 25, 1985). 
there is no need to worry about causation at all. Lots of statutes punish conduct without requiring a causal connection between conduct and harm, and some of these laws punish failures to act (e.g., laws proscribing the failure to file an income tax return). No one thinks that there are any conceptual difficulties surrounding such statutes. Why not construe bad samaritan legislation along these lines? Liability would be imposed for the failure to render assistance under specified circumstances. Period. Liability would not be for the ensuing harm, but simply for the failure to render aid. Such legislation would not be an instance of what some theorists describe as a 'result crime,' the paradigm cases of which include homicide and arson. The absence of the 'result' would not preclude liability, because liability does not depend upon the occurrence of that result. We impose liability upon drivers who fail to stop at stop signs even when no harm results from their conduct. Why not do the same with bad Samaritans? ${ }^{48}$

In addition, one might wonder whether the approach via causation confuses the prerequisites of a defensible tort claim with those of a criminal claim. Only tort demands some harm or injury.

Husak's proposal has the considerable merit of circumventing the problems of causation and, more particularly, the question whether, and if so when, failures to act have causal status. Under his proposal, it is only necessary that the person be able to exercise a beneficial influence in circumstances where it might reasonably be expected of him.

I am not, however, entirely convinced that Husak's approach provides a genuine alternative to the one I have been advancing. For once we ask why some disappointed expectations and not others are appropriate objects of criminal sanctions, I think we find that they are associated, if not with the exacerbation of harm, at least with a substantially increased risk of it. Were this association not made, there would be serious doubt about the requirement to render aid. This point is, to some extent, implicit in existing good Samaritan rules requiring assistance only in cases where a person is gravely and helplessly imperilled. It is true that in some cases a failure to render aid will not contribute appreciably to another's misery, since another bystander may provide the necessary assistance. Nevertheless, like an act of reckless endangerment, the failure has been of a kind that increases the likelihood of serious harm. Something similar, although not exactly analogous, to this analysis can be applied to the failure to file an income tax return. It is not likely that any individual who fails to file a return will harm an identifiable other. Nevertheless, failure to file a return is the kind of act that, if generally permitted, will result in socially measurable harm. Whether the punch I throw at you actually harms you is insignificant so far as criminal law is concerned. The point is that the act is of a kind that could be expected to cause or increase the likelihood of harm. 


\section{Conclusion}

As mentioned above, it has not been my intention to canvass the many problems confronting proposals to criminalize certain failures to act. ${ }^{49}$ Some I have discussed elsewhere, ${ }^{50}$ and there is a substantial literature supporting such legislation in the face of these problems. ${ }^{51}$ My task has been the more limited one of exploring again some of the deeper sources of our unease about such legislation given the uncertain status of nondoings and the role that they have in explaining failures to aid. I have attempted to uncover some of the reasons for our hesitancy in this area: the tendency to view nondoings as all-of-a-piece, and the common temptation to conflate acts with actions. In addition, I have argued that once these misgivings are overcome, some of the major theoretical difficulties that prevent viewing failures to act as legitimate candidates for criminal liability will have been removed.

I have uncovered but left virtually untouched, however, one very significant theoretical issue, namely, the reasonableness of the moral expectation to provide easy aid. This expectation underlies the characterization of certain nondoings as omissions, and in turn facilitates characterization of these nondoings as causally significant conduct. It is usual for that both defenders and opponents of good Samaritan requirements recognize that there is a moral duty to aid, they differ over the appropriateness of legislating such a duty. Nevertheless, there is another level at which the deep cleavage of opinion between defenders and detractors may emerge and, in some cases, has emerged. Where there exists a deep commitment to individualism, and social relations are viewed not as integral to individuality but only as its contingent product, even the moral expectation of easy aid will seem deeply problematic, if not altogether unintelligible. Only where individuality is seen as an essentially social achievement will the requirement to render aid be morally at home. It is at that level that the theoretical issues surrounding the criminal proscription of failures to act are in need of further debate.

49. See supra p. 174.

50. See Kleinig, supra note 45.

51. See J. Feingerg, supra note 4; Benditt, supra note 1; Woozley, supra note 1. 